\title{
FRÅ ORDBOK TIL KORPUS - OG TILBAKE? BJØRNETJENESTE OG FORFORDELE
}

\author{
LARS S. VIKØR
}

SAMANDRAG

Denne artikkelen drøftar forholdet mellom deskriptivitet og normativitet i norske ordbøker på grunnlag av to ord som har fătt nye tydingar i moderne tid i forhold til dei tradisjonelle normene: bjørneteneste og forfordele. Bruken av desse orda i moderne norsk skriftspråk blir undersøkt på grunnlag av søk i to tekstkorpus. Det viser seg at forfordele blir brukt med heilt motsette tydingar i vanleg skriftspråk. Det blir antyda at ordbøkene bør revidere tydings- og bruksbeskrivinga av dette ordet i samsvar med det mønsteret bruken viser.

\section{[1] INNLEIING}

Utgangspunktet for denne vesle undersøkinga er at ordbøker pr. definisjon er både normative og deskriptive, mens eit tekstkorpus pr. definisjon berre er deskriptivt. Visse typar av ordbøker kan rett nok seiast å vere reint normative, men dei skal eg ikkje kome inn på her. Eg tenker på dei store allmennordbøkene som inneheld både formopplysningar og definisjonar. Formopplysningane er da prinsipielt normative - definisjonane prinsipielt deskriptive. Det er dette siste eg skal ta utgangspunkt i no.

Startpoenget er da at om vi først konsulterer den prinsipielt deskriptive definisjonen til eit oppslagsord i ordboka, og så går til det reelt deskriptive korpuset og studerer bruken av ordet slik den framtrer der, så bør vi finne ein stor grad av samsvar. Dersom vi ikkje gjer det, og altså finn ut at bruken av ordet ikkje er i samsvar med definisjonen i ordboka, kan vi reagere på ulike måtar, om vi altså er vanlege "brukarar" av ordboka og korpuset: Vi kan slå fast at mange bruker ordet feil, ut ifrå ei overtyding om at det er ordboka sin definisjon som er «rett». Eller vi kan dra i tvil kva som er rett og sende inn eit spørsmål til Språkrådet eller Språkteigen. Eller vi kan akseptere begge bruksmåtane og trekke på skuldrene: "Jaja, språket utviklar seg jo." Den siste reaksjonsmåten er nok den sjeldnaste, mest begrensa til lingvistar.

Er ein leksikograf, og ansvarleg for redigering eller oppdatering av ei ordbok, står ein i ein annan situasjon. Det er dette eg har markert med "og tilbake" med spørsmålsteikn i tittelen. Skal innsikta frå korpuset reflekterast i ein revisjon av 
ordboksartikkelen? Eller uttrykt deskriptivt: Blir det gjort? Eg vil eksemplifisere denne situasjonen ved å sjå nærare på to ord som aktualiserer dette dilemmaet.

I innføringsboka Ord og ordbøker er orda bjørneteneste og forfordele nemnt som døme på ord som i bruken har fått den stikk motsette tydinga av den opphavlege, samtidig som den opphavlege tydinga også lever vidare i beste velgåande (Fjeld og Vikør 2008: 103). Under arbeidet med det seminarinnlegget som ligg til grunn for denne artikkelen (våren 2018), søkte eg på desse orda i Leksikografisk Bokmålskorpus (heretter: LBK, jf. Knudsen og Fjeld 2013) og samanlikna med definisjonane eg fann i dei store allmennordbøkene for bokmål: Bokmålsordboka (BOB), Norsk Riksmålsordbok (NRO) og NAOB, og til jamføring også i dei tilsvarande korpusa og ordbøkene for nynorsk (spesifisert nedanfor). Korleis er forholdet mellom ordbøkene og korpusa her? Det som følgjer i denne artikkelen, baserer seg på desse søkeresultata frå 2018. Sidan bokmål er hovudfokuset i denne artikkelen, bruker eg bjørnetjeneste som referanseform for dette ordet.

\section{[2] BJØRNETJENESTE}

Bjørnetjeneste kan eg gjere meg fort ferdig med. BOB definerer det slik: «velment, men uheldig hjelp som blir mest til skade» (med forklaring av opphavet i parentes: «etter La Fontaines fabel om bjørnen som skulle jage bort en flue av sin herres nese, men som i stedet knuste hodet hans»). NRO har ein tilsvarande definisjon med same opphavsforklaringa, og det same gjeld begge nynorskordbøkene (Nynorskordboka og Norsk Ordbok). Den nyaste ordboka, NAOB, har derimot to definisjonar: "1 velment, men klossete hjelp som blir mest til skade. 2 NYERE BRUK, ANSETT SOM UHELDIG stor tjeneste". Her er det fire sitatbelegg på tyding 1, ingen på tyding 2 .

I LBK er det 52 belegg på ordet, og ein gjennomgang gir eit heilt eintydig bilde, såpass at eg ikkje treng eksemplifisere og drøfte det vidare: Alle belegga følgjer den tradisjonelle definisjonen. Den dominerer altså totalt blant dei skrivande menneska som er representert i LBK; kanskje alle har høyrt La Fontaines fabel, for dei som kjenner den, vil nok ha vanskeleg for å bruke bjørneteneste som noko positivt. Her vil eg altså gi ordbøkene "godkjent" i måten å framstille dette ordet på - ut ifrå vanleg skriftleg standardspråkleg bruk.

\section{[3] FORFORDELE}

Resten av denne artikkelen skal handle om verbet forfordele, som er meir intrikat på fleire måtar. Eg startar med ordboksdefinisjonane av dette ordet, og går så inn i LBK, der ordet har 37 belegg. Det er få nok til at eg kan analysere belegga eitt for eitt på den begrensa plassen eg har her, og mange nok til at vi kan skimte eit mønster i dei ulike tydingane og bruksmåtane. 


\section{[3.1] Verbet sine tre tydingar}

Først altså definisjonane i dei tre sentrale bokmålsordbøkene:

Norsk Riksmålsordbok: «1) ved deling gi (en) mindre enn det som han har krav på; gi (en) mindre enn andre. 2) fam., gi (en) for meget»

Bokmålsordboka: «gi en mindre enn en har rett på ved fordeling»

$N A O B$ : «1 ved fordeling gi (noen) mindre enn det vedkommende har krav på; gi (noen) mindre enn andre. 2 UHELDIG, MUNTLIG gi (noen) for mye». (Her er det fire sitat på tyding 1 av Hamsun, Olaf Bull, Jostein Gaarder og Bror Hagemann, ingen på tyding 2.)

Sjølv om LBK skal vere utgangspunktet for denne artikkelen, kjem eg også til å dra inn nynorskmateriale til jamføring. Derfor siterer eg også dei to sentrale nynorskordbøkene:

Nynorskordboka: «gje (ein) mindre enn ein har krav på ved fordeling; fordele urettvist; misbyte»

Norsk Ordbok: «1) a) (ved deling) gje (ein) mindre enn det han har krav på; gje (ein) mindre enn andre; misbyta. b) (sj) gje (ein) for mykje (i høve til andre). 2) fordela (noko) ulikt, urettferdig; misbyta». (Det blir gitt eitt sitatdøme frå Syn og Segn 1967 på tyding 1a, ikkje noko på 1b, og eitt frå Dag og Tid 1975 på tyding 2.)

Her har vi altså tre tydingar, som vi kan kategorisere slik: 1) ei negativ: 'gi nokon for lite (i forhold til andre)'; 2) ei positiv: 'gi nokon for mykje (i forhold til andre)'; 3) ei nøytral: 'skeivfordele (på begge måtar)'. Vi merkar oss at den negative tydinga blir rekna som den mest tradisjonelle og vanlege, altså umarkerte, mens den positive blir markert som «fam(iliær)», «uheldig, muntlig» eller «sj(eldsynt)», eller rett og slett utelaten. Vi merkar oss òg at den nøytrale tydinga berre er representert i nynorskordbøkene.

Det er ikkje alltid så enkelt å bestemme kva for ein tydingskategori kvart belegg høyrer inn under, for det kan trengast mykje kontekst for å gjere det klart. Eg refererer no eit døme på kvar kategori der det går nokså tydeleg fram av sjølve sitatet. Først den negative tydinga:

En insolvent skyldner som begunstiger enkelte fordringshavere, forfordeler de øvrige. 
Så den positive:

Det er en metode som tillater å forfordele det kjønnet det er for lite av i en rekrutteringsprosess.

Dette er den enklaste typen å kategorisere - når det i den umiddelbare konteksten blir antyda ei motsetning til den forfordelte parten, gjennom verbet «begunstige» vs. tilstandsbeskrivinga «det er for lite av» i døma ovanfor.

Eit døme på den nøytrale bruken 'skeivfordele' har vi her:

Utposteringen av skytterne følger også prinsippet om at ingen skal forfordeles på noen måte og alle har lik sjanse til å felle viltet.

Her er det openbert at «forfordeles» omfattar både dei som får ein for god posisjon og dei som får ein for dårleg, jf. òg følgjande døme:

Gilligan hevder at Kohlberg i sin vurdering av svarene forfordeler de to respondentene.

Det er openbert at når det berre er snakk om to partar, og begge blir forfordelte, må det nødvendigvis bety at den eine får for god behandling og den andre for dårleg.

Det er ikkje alltid at tydinga av verbet går så tydeleg fram som i desse sitata. Følgjande døme, som ikkje er frå LBK, kunne tolkast både positivt og negativt:

Ny språklov styrker norsk, men forfordeler bokmålsbrukere

Men reelt er nok denne også heilt eintydig: I ingressen til den påfølgjande teksta står det at lova (eller lovutkastet, som det er snakk om her) «favoriserer nynorsk på bekostning av flertallsmålformen», altså bokmålet. Og sidan dette står på nettsidene til Riksmålsforbundet, vil nok overskrifta som er sitert ovanfor, uansett vere heilt eintydig for lesaren.

Den følgjande setninga (frå LKB) er det derimot knapt mogleg å tolke i isolasjon:

Med årets øyafestival som det fremste skrekkeksempelet hevdes det her at kvinner forfordeles.

Her er det ikkje anna å gjere enn å leite rundt i konteksten for å finne ut om den som hevdar dette (usynleggjort gjennom passivforma «hevdes»), meiner at kvinnene får for stort rom eller for lite. I dette tilfellet er det klart at «forfordeles» skal bety «favoriseres», altså heilt motsett Riksmålsforbundets praksis ovanfor. Det er ein feministisk artikkelforfattar som kritiserer ein kommentator som tar 
opp emnet «booking av kvinnelige band». Det er denne kommentatoren som hevdar at «kvinner forfordeles», altså får for stort rom. I artikkelforfattaren sine auge framstår dermed kommentatoren som ein representant for tradisjonelle, altså kvinnediskriminerande, haldningar i musikkmiljøet. Artikkelforfattaren kontrar: «Hvorfor skal man betvile øyafestivalens bookingansvarlige Claes Olsen når han sier: 'Vi booker band basert på kvalitet, ikke fordi de er enten gutter eller jenter.'»

Nokre fleire døme på «forfordele» brukt negativt vs. positivt vs. nøytralt:

Negativ tyding:

Grunnen til at faren ønsket å forfordele Esther, var at han hadde mer tiltro til sønnen og misbilliget datterens livsførsel.

Å appellere til toleranse kan derfor bli å anmode om å godta at grupper forfordeles.

Selv om et land er et demokrati, forhindrer ikke det at landets minoriteter blir forfordelt.

I Sør-Afrika forfordelte apartheidregimet det svarte flertallet og begunstiget det hvite mindretallets vannforbruk.

Dommer Lewis F. Powel jr. erklorte, på vegne av flertallet, at saksøkerne ikke hadde klare bevis for at det var en forfordelt gruppe av fattige elever $i$ dette skoledistriktet, og at Grunnloven ikke nevner utdanning som en grunnleggende rettighet.

Og du forfordelte virkelig ikke, du var raus.

Positiv tyding:

Det må foreligge garantier for at polets egne flasker $i$ hyllene ikke blir forfordelt når importmonopolet av vin og brennevin faller.

Det har vert en utbredt oppfatning blant norske leverandørbedrifter at britiske OSO har forfordelt nasjonale leverandører.

De to viktigste endringene for konsesjonssystemet var at nasjonalitet ikke kunne brukes som et kriterium så lenge søkeren hørte til EØS-området, og at norske myndigheter ikke kunne forfordele søkere som ville bruke norske varer, tjenester og arbeidskraft.

Det betyr at en forsømt sektor må forfordeles $i$ en tid fremover. 
Det ville ha veert svcert uheldig for oss å ha sittende på oss at vi forfordelte atlantakandidaturet fremfor de øvrige.

Vi har en valgdekning som forfordeler visse partier og visse ledere, etter kriterier som først og fremst er fokusert mot å maksimere seertall.

Nøytral tyding:

Fornyingen av 329 konsesjoner uten anbudsrunde var til hinder for konkurransen og kontrollen med at ingen tilbydere forfordeles.

Store summer forfordeles også via Norge 2005, som eies av Kulturdepartementet.

\section{[3.2] Objektets semantiske roller}

Både subjekt og objekt kan ha ulike semantiske roller. Dei tre viktigaste rollene er agens, patiens og recipiens (Faarlund, Lie og Vannebo 1997: 47-49). I aktive setningar er subjektet oftast agens, det direkte objektet patiens eller recipiens, og det indirekte objektet recipiens (når ei setning har både direkte og indirekte objekt). Da står recipiens for den personen eller parten (som ikkje treng vere ein person) som får eller ikkje får den aktuelle fordelen eller ressursen som er emnet for setninga. I alle dei døma eg har sitert ovanfor, er objektet recipiens.

Patiens står derimot for den storleiken som blir fordelt på dei aktuelle partane. Eg gir eit døme på dette:

Vi kjenner dem [hersketeknikkane] alle sammen ... fra de lett synlige som mobbing/erting og latterliggjøring til de mer subtile som å sette kvinnene til å lage vaktlister, holde tilbake informasjon og forfordele viktige og interessante arbeidsoppgaver.

I passivsetningar er subjektet patiens eller recipiens, mens agensrolla blir tildelt eit preposisjonsuttrykk med av eller sløyfa heilt. Døme:

Maten blir forfordelt av partene i konflikten.

Derimot ville eiendom vœere omfordelt, men fortsatt vare forfordelt.

Kjoerligheten er urettferdig og forfordelt.

I alle desse døma er subjektet patiens. 
Ein kan òg la recipiensrolla bli uttrykt i eit preposisjonsuttrykk, typisk med til:

I dag forfordeles ikke fisken til direkte anvendelse for kystbefolkningen, men til de som skal tjene penger på ressursene.

Fordelinga av semantiske roller til objektet (og til subjektet i passivsetningar) går på tvers av skilja mellom dei tre tydingane av verbet, men det ser ut til å vere eit hovudmønster: Den positive og den negative tydinga av verbet involverer for det meste recipiens-objekt, mens verbet i dei fleste av døma med patiens-objekt har den nøytrale tydinga 'skeivfordele'. Men vi har unntak: I det siste dømet, der subjektet i passivsetninga, fisken, er patiens, ser vi at det er den positive tydinga av verbet det handlar om. Og i dei to døma på den nøytrale tydinga lenger oppe som begynner på Utposteringen og Gilligan, er det recipiens-rolla som er inne i bildet. Det kan, som antyda før, skje når eit kollektiv av «recipients» omfattar partar som både kjem (eller kan kome) ut på den positive og den negative sida ved skeivfordelinga.

Ein meir spesiell situasjon får vi når verbet blir brukt i presens partisipp og dermed transformert til eit adjektiv. Da fell dei semantiske rollene bort, og det blir berre fokusert på sjølve handlinga. «Forfordelende» blir da ein eigenskap ved substantivet og ikkje ei handling i og for seg; det er tvert imot (verbal)substantivet som uttrykker handlinga. Men i konteksten kan objektet likevel bli spesifisert:

De utbetalinger som B. R. foretok ... må anses som en illojal og forfordelende handling $i$ forhold til de to eneste kreditorer som ikke fikk oppgjør.

Eit problematisk eksempel til slutt:

Ulikhetene er systematisk forfordelt, og i stor grad blir de overført fra en generasjon til en annen.

Dette gjeld sosiale forskjellar i utdanningssystemet, der elevar med lågt utdanna foreldre og minoritetsspråklege elevar systematisk kjem dårlegare ut enn dei meir ressurssterke. Det logiske innhaldet i setninga er for så vidt klart nok i samanhengen, men reint syntaktisk kan ein freistast til å meine at setninga bit seg sjølv i halen - i og med at «ulikhetene» allereie er innebygd i verbet forfordele, og ingen patiens (som må vere ekstern i forhold til verbet) ut over det er nemnt. 


\section{[3.3] Belegga}

No er tida inne til å telje belegg. Med 37 belegg er det klart at vi må ha alle moglege atterhald til dei tala vi får fram, men ein hypotese kan dei i alle fall gi grunnlag for. Eg set opp dei tre tydingane av verbet først:

Negativ tyding (ein får for lite): 15

Nøytral tyding (skeivfordeling): 12

Positiv tyding (ein får for mykje): 10

Dette er språkbruk som for det meste er yngre enn 2000, i eit par tilfelle går belegga tilbake til 1980-talet. Ei tilsvarande teljing av dei semantiske rollene til objektet gir dette resultatet:

\section{Recipiens: 27}

Patiens: 8

Ikkje noko objekt (presens partisipp av verbet): 2

Kryssar ein så kriteria, finn ein at seks av patiens-objekta knyter seg til den nøytrale tydinga, eitt kvar til dei to andre. Dei to døma på bruk av presens partisipp knyter seg til den negative tydinga.

Ser ein på kjeldene for belegga, finn ein at det stort sett dreiar seg om sakprosa i bokform, nokre få tidsskrift, nokre lærebøker, og ein del juridiske tekster. Nesten ingen aviser, men tre belegg er frå Bergens Tidende i 1995. Tidsmessig ligg dei fleste belegga mellom 2000 og 2012, men nokre er frå midt på 1980-talet og 1990-talet. Det er ikkje mogleg å finne noko mønster for fordelinga av dei ymse tydingane på tidsrom og kjeldetype.

Eg har også tatt ein kik på det nynorske tekstkorpuset som er brukt i Norsk Ordbok. Det har eit noko anna kjeldegrunnlag, med stor vekt på aviser, nesten alt frå 2000-talet. Det er ikkje så overraskande når det gjeld eit ord som knyter seg mest til den moderne språkbruken og mindre til den tradisjonelle på nynorsk. Dei avisene det er mest av, er Dag og Tid, Firda, Hallingdølen og Sogns Avis. Belegg frå tidsskrift og bøker er meir spreidde. Også her er fleire belegg tvilsame eller vanskelege å tolke og dermed å avgrense, så tala baserer seg på skjønn, men det store bildet blir nok likevel nokolunde dekkande. Eg nøyer meg her med å sjå på tydingsfordelinga; dei semantiske rollene er mindre interessante, for recipiens-objekta dominerer her òg.

Eg finn ca. 40 belegg som er relevante og kategoriserbare i dette materialet. Fordeler vi dei på dei tre tydingane av verbet, ser vi dette mønsteret (igjen med det atterhaldet at tala er omtrentlege og ikkje presise): 
Positiv tyding: 20

Negativ tyding: 12

Nøytral: 8

Altså ei klar overvekt på den positive tydinga, samtidig som den negative også er godt representert.

Vil ein prøve å forklare denne skilnaden mellom bokmåls- og nynorskmaterialet, så er det neppe særleg fruktbart å peike på målforma. Bruken spriker så mykje i begge målformene at det må vere eit trekk ved norsk språkbruk heva over skilnaden mellom bokmål og nynorsk. Derimot kunne ein kanskje sjå nærare på sjangeren kjeldene høyrer til: Det verkar ikkje så overraskande at eit utval belegg frå aviser frå etter 2000 gir større utslag for den positive tydinga enn eit utval sakprosatekster i bokform, der ein kan tenke seg at profesjonelle språkvaskarar har vore meir inne i bildet enn i avisredaksjonane. Ei tilsvarande gransking basert på eit aviskorpus på bokmål kunne kanskje ha kasta lys over det. Denne artikkelen har eit format som ikkje tillèt ei slik utviding, men det står alle fritt å supplere den undersøkinga eg har gjort.

\section{[3.4] Og kva skal leksikografane gjere?}

No er tida inne til å kaste eit blikk på ordbøkene att. Spørsmålet er om ikkje dei dataa eg legg fram her, kvalitetssikra med supplerande undersøkingar, burde verke tilbake på ordbøkene, slik at begge tydingane blir greidd betre ut, og at kvalifiseringar som «familiært» og «muntlig» blir modifisert eller tatt ut. For «forfordele» i tydinga «gi for mykje» er openbert ein del av vanleg skriftspråksbruk i dag. Om det er «uheldig», må det vere opp til kvar enkelt å synse om.

Eit par av nynorskbelegga er tatt frå drøftingar av sjølve ordet og tydinga. I Hallingdølen skriv Dag Wollebæk i 2009:

I Hallingdølen tysdag 12.5 går det fram at bustyraren for Elkjøp Nesbyen AS meiner at Elkjøp Norge og Nes Prestegjelds Sparebank vart forfordelt i forkant av konkursen i Elkjøp. Og då meinte bustyraren at desse hadde fått for mykje samanlikna med andre kreditorar. Om det er Hallingdølen eller bustyraren som har gått $i$ «forfordelingsgrøfta» veit eg ikkje. Men å bli forfordelt tyder faktisk å få for lite. Svært mange trur det er motsett. Derfor eit råd til alle journalistar - og alle andre skrive- og taleføre. Ikkje bruk ordet forfordele; ein risikerer anten å bli misforstått - eller ein brukar det feil.

Og nokre år før, i 2000, skriv Johan Brox i Dag og Tid: 
... ordet forfordelt ... tyder diskriminert, men dei fleste skriv og les ordet i motsett tyding. Når korkje avsendar eller mottakar veit kva den andre legg i orda, er dei ubrukelege for alle. Til dei eventuelt får eit nytt innhald som alle er samde om.

Denne konklusjonen finn vi att i utgangspunktet for denne artikkelen, Fjeld og Vikør 2008: 103:

Da vi lånte det tyske vervorteilen inn i norsk, betydde det at den som ble forfordelt, fikk mindre enn han/hun skulle ha i en delingsprosess. I dag mener mange at den forfordelte får mer enn det som rimelig er, og med den betydningen kan ordet fungere greit kommunikativt dersom begge parter aksepterer "misforståelsen". Da har ordet rett og slett fått en annen betydning. Verre er det dersom språkbrukerne er uenige om betydningen, slik at en aldri kan vite hva en annen språkbruker mener med ordet. Slik er nok situasjonen for forfordele i norsk i dag, og i et slikt tilfelle kan en bli nødt til å advare mot å bruke ordet i det hele tatt uten presisering.

\section{[3.5] Opphav og nerskylde språk}

Ordbøkene (og Fjeld og Vikør) gir opp tysk vervorteilen som opphav til forfordele. Dette ordet finst ikkje i moderne tyske ordbøker, men det er beskrive i Grimms historiske Deutsches Wörterbuch (der stava vervortheilen) med ei negativ tyding som er klart sterkare enn den moderne norske, noko i retning av 'bedra', 'skade' o.l. Ordbog over det danske Sprog plasserer dette ordet i det "eldre nyhøgtyske" språkstadiet.

Ein sjekk i nederlandske standardordbøker viser det same mønsteret: vervoordelen, som det heiter der, er der belagt frå 15- og særleg 1600-talet, med den same tydinga som i tysk. I den store historiske Woordenboek der Nederlandsche Taal har dette ordet (stava vervoordeelen etter rettskrivinga fram til 1947) fått ein relativt lang artikkel, men der har ordet i den positive tydinga ('hjelpe') også fătt ein liten artikkel der det går fram at det i denne tydinga berre er belagt som dialektord frå tiåra rundt 1900, og da tydeleg inspirert av substantivet voordeel 'fordel'. I moderne skriftspråk er dette verbet likevel utdøydd og erstatta av to ord som i motsetning til vårt forfordele er fullstendig eintydige: bevoordelen står for den positive tydinga og benadelen for den negative. Preposisjonen na er det motsette av voor, altså 'etter', og nadeel er det vi kallar ulempe. For nederlendingane finst altså ikkje dette problemet lenger.

Svenskane ser også ut til å ha unngått det; förfördela blir eintydig definert med den negative tydinga i alle ordbøker som eg har konsultert. Men bruken i svensk 
har eg ikkje undersøkt.

I dansk liknar stoda meir på den norske: forfordele får den negative tydinga i alle ordbøker, bortsett frå ei, og den er viktig: Seksbandsverket Den danske ordbog fører opp begge tydingane: den tradisjonelle negative som tyding 1 , den positive som tyding 2, og der blir det opplyst at den er belagt frå 1964 av og blir mest brukt blant yngre menneske. "Denne brug regnes af mange for ukorrekt", melder ordboka.

Både i dansk og i norsk er det vel rimeleg å tenke seg at denne positive tydinga har utvikla seg i språkbruken på grunnlag av substantivet fordel, slik vi såg eit lite utslag av i nederlandsk: Ein lite gjennomsiktig tradisjonell bruk blir omtolka på grunnlag av eit notidig språkbruksmønster som er umiddelbart forståeleg for nye generasjonar. Dermed ser vi ein parallell til det som har skjedd med bjørneteneste i moderne norsk talemål.

\section{[4] DESKRIPTIVITET VS. NORMATIVITET}

Utgangspunktet for denne drøftinga er forholdet mellom deskriptivitet og normativitet i ordbøkene. Eg skreiv at i dei store allmennordbøkene er formopplysningane (rettskriving og bøying) prinsipielt normative, mens definisjonane og andre tydings- og bruksopplysningar må vere prinsipielt deskriptive.

Grensa mellom deskriptivitet og normativitet er likevel ikkje hoggen i stein (jf. Fjeld og Vikør 2008: 138). Det er fordi den faktiske språkbruken aldri foregår i eit normativt tomrom. Når NAOB supplerer ein definisjon med markeringar som «NYERE BRUK; ANSETT SOM UHELDIG» (bjørnetjeneste tyding 2) og «UHELDIG, MUNTLIG» (forfordele tyding 2), kan det reknast som deskriptivt i seg sjølv: Leksikografen beskriv faktisk eksisterande haldningar i språksamfunnet. Når Norsk Ordbok under forfordela tyding 2 b skriv «sj(eldsynt)» kan det i enda høgare grad reknast som deskriptivt. Men slike kvalifiseringar, som mest baserer seg på leksikografens oppfatning av situasjonen i språksamfunnet, er risikable. Korpuset kan stille leksikografen i skammekroken: Det er som vist ovanfor klart at forfordele i dag er vanleg både i den positive og den negative tydinga i den skriftlege språkbruken; bruksmarkeringane i NAOB og i Norsk Ordbok (og NROs «fam(iliært)») er openbert rett og slett feil i dag. (For Norsk Ordbok har vi den orsakinga at artikkelen forfordela stod i eit hefte som kom ut i 1989, men det er slett ikkje sikkert at opplysninga «sj(eldsynt)» stemte da heller; jf. opplysninga i Den danske ordbog ovanfor.) Opplysninga «NYERE BRUK» under bjørnetjeneste tyding 2 i NAOB er meir «objektiv», og truleg rimeleg enkel å dokumentere. «ANSETT SOM UHELDIG» er ei normativ utsegn i deskriptiv forkledning, det går ikkje fram kven som «anser» dette. Men det at denne tydinga manglar i korpuset, er ein sterk indikasjon på at kvalifiseringa reint faktisk stemmer, og brukarens intuitive 
kunnskap om språksamfunnet vil nok stø opp under denne konklusjonen; i alle fall gjeld dette litt eldre språkbrukarar, og i alle fall inntil vidare.

\section{LITTERATUR}

Faarlund, Jan Terje, Svein Lie \& Kjell Ivar Vannebo. 1997. Norsk referansegrammatikk. Oslo: Universitetsforlaget.

Fjeld, Ruth Vatvedt \& Lars S. Vikør. 2008. Ord og ordbøker. Innføring i leksikografi og leksikologi. Kristiansand: Høyskoleforlaget.

Knudsen, Rune Lain \& Ruth Vatvedt Fjeld. 2013. LBK2013: A balanced; annotated national corpus for Norwegian Bokmål. I Proceedings of the workshop on lexical semantic resources for NLP at NODALIDA 2013; May 22-24; 2013; Oslo; Norway. NEALT Proceedings Series 19.

\section{ORDBØKER:}

Bokmålsordboka. Boye Wangensteen. 2006. Oslo: Universitetsforlaget / Kunnskapsforlaget (1. utg. 1986 ved Marit I. Landrø og Boye Wangensteen).

Den Danske Ordbog. Ebba Hjorth o.a. 2003-05. København: Det Danske Sprog- og Litteraturselskab.

Deutsches Wörterbuch. I-XXXIII. Jacob og Wilhelm Grimm o.a. 1838-1962.

Norsk Ordbok. Ordbok over det norske folkemålet og det nynorske skriftmålet I-XII. Alf Hellevik o.a. 1966-2016. Oslo: Det Norske Samlaget.

Norsk Riksmålsordbok I-IV. Trygve Knudsen og Alf Sommerfelt 1937-57. Oslo: Aschehoug.

Nynorskordboka. Marit Hovdenak o.a. 2006. Oslo: Det Norske Samlaget (1. utg. 1986).

Ordbog over det danske Sprog I-XXVIII. Verner Dahlerup o.a. 1918-56. København: Det Danske Sprog- og Litteraturselskab.

Woordenboek der Nederlandsche Taal I-XXIX. Matthias de Vries o.a. 1882-1998. Den Haag: Martinus Nijhoff.

ELEKTRONISKE KJELDER:

Leksikografisk bokmålskorpus - LBK. http://www.hf.uio.no/iln/tjenester/kunnskap/samlinger/bokmal/veiledningkorpus/ 
NAOB: Det Norske Akademis Ordbok. https://www.naob.no

Norsk Ordboks Nynorskkorpus. http://no2014.uib.no/korpuset/conc_enkeltsok.htm

KONTAKT

Lars Vikør

Professor emeritus, Institutt for lingvistiske og nordiske studier, Universitetet i Oslo

l.s.vikor@iln.uio.no 
